\title{
Amando de olhos abertos Emma Goldman e o dissenso político nos EUA*
}

\author{
Loving with open eyes \\ Emma Goldman and the political dissent in the Unites States
}

\author{
Cecilia azevedo \\ Professora Adjunta do Departamento de História da \\ Universidade Federal Fluminense \\ Doutora em História Social pela Universidade de São Paulo \\ ceciliasa@uol.com.br
}

\begin{abstract}
RESUMO Este artigo apresenta a trajetória de Emma Goldman, grande nome do anarquismo, pacifismo e feminismo nos EUA, procurando apresentá-la como uma representante da chamada tradição de dissenso neste país que, ao longo de toda sua história, tem disputado os sentidos a serem atribuídos aos ideais nacionais. Em meio à atual guerra no Iraque, a memória e o legado de Emma Goldman vêm sendo recuperados no embate político em torno do sentido do americanismo.
\end{abstract}

Palavras-chave Emma Goldman, pacifismo, anarquismo

ABSTRACT This article presents the life of Emma Goldman, who played a central role in the history of anarchism, pacifism and feminism in the United States. In the present days, when a new war is taking place in Iraq, the

* Artigo recebido em 31/05/2007. Autora convidada.

** (Este texto é uma versão modificada de uma comunicação apresentada no VII Encontro Internacional da ANPHLAC - Associação Nacional de Pesquisadores de História Latino-Americana e Caribenha -, realizado em outubro de 2006, na Pontifícia Universidade Católica de Campinas). 
memory and legacy of Emma Goldman are being reassessed amidst the debate over the political meaning of Americanism.

Key words Emma Goldman, pacifism, anarchism

No dia 4 de maio de 1886 uma bomba explodiu na Haymarket Square, em Chicago, no momento em que a polícia cercava uma manifestação de trabalhadores em defesa da greve geral pela jornada de trabalho de oito horas. Sete policiais e um número muito maior de manifestantes morreram neste episódio. A identidade de quem lançou a bomba nunca foi determinada, mas após a prisão de dezenas de líderes socialistas e anarquistas, a maioria de descendência germânica, oito foram indiciados. Paralelamente, teve início pela imprensa uma intensa campanha contra o movimento sindical, especialmente o de inspiração anarquista, trazido pela "escória" dos imigrantes europeus, responsabilizados ainda por todo tipo de desordem e corrupção dos costumes "tradicionais". Além das greves, crimes, prostituição e alcoolismo seriam também mazelas associadas às "hordas" estrangeiras, segundo matérias alarmistas publicadas em vários jornais.

Dos indiciados, quatro foram enforcados, um cometeu suicídio na prisão ${ }^{1}$ e dois foram condenados à prisão perpétua. O júri seguiu, assim, a recomendação do promotor, que, em seu apelo final ao júri, afirmou que enforcar os acusados seria a única maneira de salvar as instituições e a sociedade norte-americana.

A repercussão desses episódios, que marcaram o movimento sindical norte-americano, e a disputa pela sua memória merecem ser recuperados de modo a demonstrar a intensidade dos conflitos políticos e ideológicos que agitavam os EUA na virada do século XIX para o XX. Em 1893, um monumento em memória dos condenados, transformados em mártires da causa dos trabalhadores, foi inaugurado diante de oito mil pessoas no cemitério de Waldheim.

Quatro anos antes, em 1889, uma estátua em bronze de um policial foi construída na própria Haymarket Square. Um ano depois ocorreu a primeira tentativa de explosão do monumento, este foi transferido para outro local e nos pés da escultura do policial foram inscritas as seguintes palavras: "Em nome do povo, eu determino a paz". A paz, no entanto, não viria. No dia 4

1 Albert Parsons, August Spies, Adolph Fischer, George Engel (enforcados) e Louis Lingg, que cometeu suicídio na prisão. August Spies era o editor do jornal anarquista The Alarm. Juntos, Parsons e Spies mobilizavam os trabalhadores da comunidade germânica de Chicago convocando manifestações e desfiles. A organização que criaram em 1881, a I.W.P.A. - International Working People's Association - tinha no máximo 5 mil membros, mas sua estratégia era tão confrontacional que dificultava influência e penetração maior. 
de maio de 1927, um carro se chocou contra o monumento, forçando uma nova mudança. Em 1969, uma bomba lançada pelos Weathermen, uma dissidência do Students for a Democratic Society, ${ }^{2}$ destruiu boa parte do monumento. Em 1970, uma outra bomba danificou-o novamente, obrigando a que se realizasse uma segunda restauração. Depois de restaurado, o monumento passou a ser vigiado por guardas 24 horas por dia. Por fim, dois anos depois, o prefeito resolveu transferir o monumento para a sede da polícia de Chicago.

Por sua vez, o monumento aos mártires no cemitério de Waldheim foi transformado em local de peregrinação da esquerda americana e, em 1997, reconhecido como Monumento Histórico Nacional. Ao lado dos mártires, foram enterrados outros grandes nomes da esquerda, ${ }^{3}$ entre eles Emma Goldman.

A história dos mártires da Haymarket Square é sempre referida nas notas biográficas de Emma Goldman, que se tornou um dos principais nomes do anarquismo e que, como outros imigrantes, foi peça fundamental em diferentes movimentos sociais e políticos que tiveram curso nos EUA nas primeiras décadas do século XX.

Emma nasceu em 1869, na Lituânia, parte do império russo onde se concentrava grande número de judeus perseguidos durante o tsarismo. Abrigando uma diversidade de grupos étnicos, o governo da Rússia implementava políticas no sentido de sua assimilação. Em relação aos judeus, forçava o abandono do yiddish pelo russo e do judaísmo pelo cristianismo. Mas, o efeito acabou sendo o oposto. O apego à ortodoxia religiosa foi assumido por muitos como única forma de resistir à perseguição e garantir uma base para sua identidade. Emma Goldman sofreu, assim, desde a infância, não apenas com a pobreza e a discriminação, mas com o rigor religioso de sua família, especialmente de seu pai.

Em 1881, logo após o assassinato do czar Alexandre II, Emma e sua família seguem para São Petersburgo em busca de melhores condições de

2 Constituído inicialmente como um departamento estudantil da LID - League for Industrial Democracy, vinculada ao partido Socialista, a SDS não tardaria a romper com ela, assumindo protagonismo nas lutas estudantis e na chamada New Left. Nos seus nove anos de existência, a SDS transitou de uma postura reformista, com base nos princípios da não-violência, buscando aproximação com a SNCC - Students Non-Violent Coordinating Commitee -, para a apologia da luta armada revolucionária contra o Estado norte-americano e o capitalismo. Demonizando a "América", se identificaram com as revoluções anticoloniais e antiimperialistas que estouravam no Terceiro Mundo. No âmbito interno, a facção Weatherman propôs-se a combater o "sistema" por meio de ações armadas clandestinas. Ver SOUSA, Rodrigo Farias de. De Port Huron aos Weathermen: Students for a Democratic Society e a Nova Esquerda Americana (1960-1969). Rio de Janeiro: Universidade Federal Fluminense, 2007 (História, Dissertação de Mestrado); e GITLIN, Todd. The Sixties: years of hope, days of rage. New York: Bantam Books, 1993.

3 Entre os personagens mais ilustres, pode-se citar Bill Haywood, líder dos wooblies - a mais importante organização anarco-sindicalista dos EUA - Industrial Workers of America; Joseph Dietzgen, filósofo alemão que emigrou para os EUA e dedicou-se ao estudo do materialismo dialético; Voltairine de Cleyre, ao lado de Emma, um grande nome do anarquismo e feminismo nos EUA; Ben Reitman, anarquista, parceiro e amante de Emma; Lucy Parsons, líder sindical anarquista e posteriormente comunista, que nasceu escrava; William Z. Foster, por longo tempo Secretário-Geral do Partido Comunista dos EUA e líder sindical, com passagem pelo Partido Socialista; Elizabeth Gurley Flynn, importante liderança no IWW, do Partido Comunista, fundadora da American Civil Liberties Union. 
vida. Emma, então uma adolescente, se encanta com a atmosfera radical da cidade, onde grupos revolucionários inspirados em Bakunin pregavam a violência como estratégia revolucionária. Para muitos judeus radicais, naquele contexto, em primeiro lugar deveria vir a política e não a religião, já que assumiam que os problemas dos judeus se resolveriam quando um novo regime político os resgatasse da pobreza. Identificada com o heroísmo dos revolucionários, Emma rebela-se na esfera doméstica, resistindo a um casamento arranjado por seu pai e, em 1885, aos 15 anos, parte para os EUA para se juntar a uma irmã mais velha já radicada em Nova York.

Ao chegar, Emma começou a trabalhar numa fabrica têxtil, ganhando US\$2,50 por semana, por uma jornada diária de dez horas e meia de trabalho. Emma vivencia então a onda de greves pela jornada de oito horas de trabalho do ano de 1886 e o caso de Haymarket Square, que a comove profundamente. Os mártires de Chicago, a seus olhos, em tudo se assemeIhavam aos revolucionários russos que, por lutarem por seus ideais, foram executados por um governo repressivo.

Emma acompanhou avidamente pelos jornais o julgamento dos acusados, interessando-se cada vez mais pela causa que lhes era atribuída - o anarquismo.

Emma Goldman integrava-se então à comunidade de imigrantes pobres empregados no setor industrial das mais importantes cidades dos EUA, como Chicago, Filadélfia e Nova York. Para se ter uma idéia de seu peso numérico, vale mencionar que, em 1900, 4/5 da população de Nova York, principal porto de entrada do país, eram compostos por estrangeiros ou filhos de estrangeiros. O mesmo valia para 2/3 dos habitantes de Boston e Filadélfia e 3/4 da população de Chicago.

Essa nova onda de imigração vai provocar nos EUA, não apenas o clima de xenofobia antes mencionado, mas discussões político-filosóficas sobre o "verdadeiro americanismo", que envolverão discussões sobre o papel dos EUA no mundo e as contradições entre seu proclamado ideário de defesa da paz, da liberdade e da democracia e o belicismo crescente de sua política externa, a partir da guerra hispano-americana, a primeira travada fora do continente. ${ }^{4}$ Nesse contexto, conhecido como era do Progressivismo, inúmeros intelectuais envolveram-se em acalorados debates sobre as reformas necessárias ao aperfeiçoamento da democracia, com vistas a reduzir as desigualdades sociais flagrantes ${ }^{5}$ e as possibilidades e vias de americanização dos imigrantes. Em True Americanism: Progressive Era Intellectuals

4 Sobre este assunto e especificamente o embate entre William James e Theodore Roosevelt, ver AZEVEDO, Cecília Pelo avesso: crítica social e pensamento político-filosófico no alvorecer do 'século americano': William James e o Pragmatismo. Diálogos. Revista do Departamento de História da Universidade Estadual de Maringá, Maringá, v.7, p.25-36, 2003.

5 Flávio Limoncic recupera esse debate em LIMONCIC, Flávio. A promessa da vida americana: Herbert Croly, as 'discriminações construtivas' e a questão do Estado norte-americano. In: REIS Filho, Daniel Aarão. (org.) Intelectuais, história e política. Rio de Janeiro: 7 Letras, 2000, p.75-97. 
and the Problem of Liberal Nationalism, Jonatham Hansen ${ }^{6}$ recupera vários intelectuais e políticos que assumiam perspectivas diversas.

Segundo Theodore Roosevelt, por exemplo, para evitar a falência do espírito que presidira a fundação e expansão da nação, seria preciso que todos pensassem, trabalhassem e vivessem "exclusivamente como Americanos", o que significava que os imigrantes, além de esquecer antigas lealdades e vínculos, deveriam aderir aos princípios do individualismo liberal e da ética puritana do trabalho. Para Roosevelt, os anarquistas, pela perversão que procuravam promover nas relações de trabalho, e as "raças resistentes à assimilação" não se qualificariam como verdadeiros americanos. ${ }^{7}$ Num outro sentido, Louis Brandeis, juiz da Suprema Corte durante a presidência de Wilson, apontava que a "americanização" dos imigrantes dependeria não de sua disposição para dominar o inglês e absorver os costumes locais, mas da capacidade do sistema para estender a esses recém-chegados os direitos e as condições de vida e trabalho compatíveis com as promessas da democracia liberal. Brandeis integraria, assim, uma corrente heterodoxa em relação ao liberalismo clássico que impeliria inúmeros intelectuais que, desde então, rejeitaram teorias racialistas e passaram a defender a associação entre americanismo e pluralismo cultural. ${ }^{8}$

Essa vertente liberal, recentemente revalorizada, integrou um universo mais amplo, onde outras correntes de dissenso tiveram curso. Assim, antes de voltar à trajetória de Emma Goldman, convém apresentar algumas questões sobre a chamada tradição de dissenso nos EUA e as visões mais correntes a respeito dos movimentos considerados de esquerda, especialmente a ênfase em suas fraquezas e contradições, que tem como efeito colocar nas sombras a trajetória e o significado de figuras como a de Emma Goldman.

Embora a disputa entre diferentes projetos políticos tenha acompanhado a formação da nação desde o século XVIII, expressando não apenas um confronto de idéias políticas, mas lutas sociais concretas, ${ }^{9}$ a corrente do consenso dominou por muito tempo a historiografia dos EUA, ${ }^{10}$ contribuindo para a solidificação de mitos nacionais, entre eles o da excepcionalidade da experiência norte-americana, capaz de instituir a liberdade sobre a base de

6 In: KAZIN, Michael e MCCARTIN, Joseph A. (eds.) Americanism: New Perspectives on the History of a Ideal. Chapel Hill: The University of North Carolina Press, 2006, p.73-89.

7 KAZIN, Michael e MCCARTIN, Joseph A. (eds.) Americanism, p.73.

8 KAZIN, Michael e MCCARTIN, Joseph A. (eds.) Americanism, p.74.

9 WILENTZ, Sean. Chants Democratic: New York City \& the rise of American working class. New York/Oxford: Oxford University Press, 1984; KERBER, Linda. The Revolutionary Generation: Ideology, Politics and Culture in the Early Republic. In: FONER, Eric (org.) The New American History. Philadelphia: Temple University Press, 1990; PAMPLONA, Marco Antônio. Revoltas, República e Cidadania: Nova York e Rio de Janeiro durante a consolidação da ordem republicana. Rio de Janeiro: Record, 2003; LEMISH, Jesse. A Revolução Americana vista desde el Fondo. In: Ensayos inconformistas sobre los Estados Unidos. Barcelona: Ediciones Peninsula, 1976.

10 STERNSHER, B. Consensus, Conflict and American Historians. Bloomington: Indiana University Press, 1975. 
uma sociedade indivisa e livre de conflitos sociais, já que, desde a origem, teria contado com recursos abundantes. ${ }^{11}$

Desde os anos 60, com o advento da historiografia da New Left, no entanto, inúmeros pesquisadores têm se dedicado a revelar a face do dissenso que a narrativa oficial procurou ocultar, recuperando movimentos de resistência e protesto, experiências sociais que deram origem a projetos políticos diferenciados que disputam o sentido a ser atribuído ao passado e à identidade nacional. ${ }^{12}$

Nessa ótica, Martinot aponta que movimentos sociais de natureza diversa nos EUA - sindical, em defesa dos direitos civis, pacifista, feminista, ambientalista etc. - forjaram sentidos alternativos de cidadania com base na democracia participativa. ${ }^{13}$ Valendo-se de tradições e práticas intelectuais passadas, mas reinventando-as, identificaram novos problemas, desenvolveram novos conceitos e lutaram pela preservação da participação nos espaços públicos. Partidos, movimentos, comunidades, formas de comunicação e de relação interpessoal, papéis sexuais, identidades e modelos alternativos de expressão política foram criados e difundidos.

Como então qualificar ou diferenciar as expressões de dissenso na sociedade e na história norte-americanas? Martinot, por exemplo, defende diferenciar resistência e protesto. O protesto traria implícito que o diálogo com o poder é ainda possível, assumindo-se que existe disposição por parte deste em considerar as demandas apresentadas. A idéia de resistência implicaria uma crise de maior proporção, uma vez que exigiria construir um espaço inexistente, criar uma nova ordem onde seria possível vivenciar o que é demandado. Neste processo, novas linguagens e novos sentidos de identidade e de comunidade são produzidos, o que equivaleria à emergência de uma cultura política alternativa. ${ }^{14}$

No vocabulário político, mas também no acadêmico, a designação radical é muito freqüentemente utilizada para qualificar projetos e movimentos que desafiam os limites da ordem liberal e capitalista, demandando

11 ROBERTSON, James Oliver. American Myth, American Reality. New York: Hill \& Wang, 1994; ZELINSKY, Willbur. Nation into State. The shifting symbolic foundations of American nationalism. Chapel Hill \& London: University of North Carolina Press, 1988.

12 Recentemente foi publicada a coletânea: KAZIN, Michael e MCCARTIN, Joseph A. Americanism: New Perspectives on the History of an Ideal.

13 MARTINOT, Steve and JAMES, Joy. (eds.) The Problems of Resistance: Studies in Alternate Political Cultures. In: Radical Philosophy Today. v.2. New York: Humanity Books, The Proceedings of the Radical Philosophy Association National Meeting, 1998.

14 MARTINOT, Steve e JAMES, Joy. (eds.) The nature of resistance. In: The Problems of Resistance: Studies in Alternate Political Cultures. Sem pretender estabelecer qualquer tipologia, James Jasper defende que movimentos de protesto são especialmente ricos por permitirem a elaboração de novos sentidos e perspectivas políticas, morais, cognitivas, emocionais. Ver JASPERS, James. The Art of Moral Protest: Culture, Biography and Creativity in Social Movements. Chicago/London: The University of Chicago Pres, 1997, p.XII-XIII. O conceito de cultura política tem sido retomado pelos historiadores e empregado com o sentido de enfatizar a existência de culturas políticas plurais no interior das sociedades nacionais. BERNSTEIN, Serge V. A Cultura Política. In: RIOUX, Jean-Pierre e SIRINELLI, Jean-Francois. (orgs.) Para uma história cultural. Lisboa: Editorial Estampa, 1998, p.349-363 e SOIHET, Rachel; BICALHO, Maria Fernanda Baptista e GOUVÊA, Maria de Fátima. (orgs.) Culturas Políticas: ensaios de história cultural, história política e ensino da História. Rio de Janeiro: Mauad/Faperj, 2005. 
mudanças pautadas nas idéias de igualdade e liberdade, compreendidas como algo além da virtual igualdade de oportunidades e dos padrões de comportamento, estratégias e formas de expressão política usualmente aceitos. É evidente que o atributo "radical" depende do contexto. Lutas e projetos considerados radicais no momento de sua eclosão, uma vez vencedores, tornam-se componentes da nova ordem, já que faz parte do próprio processo de construção da hegemonia a incorporação de elementos políticos e sociais anteriormente excluídos. ${ }^{15}$ Portanto, em relação à incorporação dos projetos considerados radicais, devemos recusar tanto a leitura conservadora muito corrente que enfatiza a idéia de que a sociedade norte-americana, perseguindo sempre o equilíbrio, rejeita extremismos, quanto a perspectiva pessimista e apocalíptica que acaba por adotar a tese do fim da história por enxergar apenas a potência do sistema dominante que tudo devora e esteriliza. ${ }^{16}$

Esta última perspectiva está presente nas análises sobre o movimento sindical. São muito correntes as avaliações de que o movimento sindical norte-americano foi dominado por uma perspectiva pragmática, mostrandose muito pouco permeável às ideologias de esquerda, repudiando as teses marxistas da luta de classes, especialmente a violência como estratégia ou tática de luta sindical. Várias explicações são levantadas: a perspectiva teleológica do marxismo e suas previsões a respeito da crise inevitável do capitalismo, que não encontrariam eco num ambiente de vertiginoso crescimento econômico; o racismo, fator de divisão e discriminação dos trabalhadores não especializados; a falta de um partido que assumisse a causa e reforçasse a identidade dos trabalhadores, etc. Assim, embora em muitos momentos apresentasse uma face radical, o movimento dos trabalhadores teria sido vencido quer pela ideologia burguesa, quer pela repressão violenta, que incluía a própria espoliação física e simbólica do trabalhador, submetido aos modelos taylorista e fordista. ${ }^{17}$

Um autor que merece destaque é John Patrick Diggins e seu livro The rise and fall of the American Left. ${ }^{18} \mathrm{O}$ próprio título do livro indica claramente sua perspectiva de que a esquerda norte-americana cumpriu um ciclo que terminou em queda e impotência irremediáveis. Diggins percebe a existência de quatro gerações na esquerda norte-americana: a esquerda lírica, a velha esquerda, a nova esquerda e a esquerda acadêmica. ${ }^{19}$ É significativo que

15 POPE, Daniel. (ed.) American Radicalism. Malden, Massachusets \& London: Blackwell Publishers, 2001.

16 AZEVEDO, Cecília; SOUSA, Rodrigo e CHAVARRY, Gabriel. Modernidades alternativas: o confronto de culturas políticas e a tradição de dissenso nos EUA. In: REIS FILHO, Daniel Aarão. (org.) Modernidades alternativas nas Américas. (no prelo).

17 FERREIRA, Jorge. O movimento operário norte-americano. São Paulo: Ática, 1995.

18 DIGGINS, John Patrick. The rise and fall of the American left. New York/London: W.W. Norton \& Company, 1992.

19 A designação "nova esquerda" atribuída a várias organizações e movimentos dos anos 60, assinalava a busca de uma nova identidade por oposição à geração anterior, chamada então de "velha esquerda", que vivera seu auge na Depressão dos anos 30, associada às lutas sindicais e aos Partidos Comunista e Socialista. À esquerda no pós-Vietnã, a partir dos anos 80 , teria se refugiado na academia, sem associação expressiva com movimentos 
Diggins não associe o movimento sindical da virada do século, de inspiração anarquista e socialista, a nenhuma geração de esquerda, retratando suas principais ações e lideranças num capítulo anterior, significativamente intitulado "Strangers in the Land". Emma é retratada como uma feminista radical no capítulo dedicado à esquerda lírica, cujo reduto se localizava em Greenwich Village, em Manhattan, Nova York. ${ }^{20}$ A esquerda lírica é configurada como uma esquerda poética, romântica, de salão, dissociada dos movimentos sociais, especialmente o operário. Nenhuma semelhança com a experiência política de Emma, cujo envolvimento com o movimento sindical foi o ponto de partida de sua trajetória política. ${ }^{21}$

Goldman iniciou sua militância política ao aproximar-se do círculo de intelectuais anarquistas russos que pregava a violência revolucionária. Conheceu então em Nova York, num ambiente nada semelhante ao do Village de Manhattan, uma das figuras mais importantes de sua vida - Alexander Berkman amante por apenas alguns anos, mas fiel companheiro político até sua morte. Em pouco tempo, Goldman revelou-se grande oradora, primeiramente em alemão, língua de boa de parte de sua audiência de então, composta majoritariamente por trabalhadores imigrantes, e posteriormente em inglês, que passaria a ser o idioma em que melhor se expressaria, inclusive, por escrito.

Mas tanto ela como Berkman estavam convencidos então da necessidade de empregar outros recursos, além da retórica. A oportunidade surgiu com a deflagração de uma greve pelos trabalhadores da Carnegie Steel Corporation. Berkman imaginou que um atentado contra um representante da empresa servisse como catalisador das energias revolucionárias dos trabalhadores. Como não tinham dinheiro, Emma decidiu que seria prostituta por uma noite para conseguir o suficiente para comprar a arma que detonaria a revolução. Assim, numa noite de julho de 1892, aos vinte e três anos, Emma Goldman posta-se junto com outras moças numa rua de Manhattan. Absolutamente embaraçada, acaba conseguindo apenas dez dólares de um senhor que se apieda e lhe oferece o dinheiro graciosamente..$^{22}$ Mas dez dólares não eram suficientes. Para reunir a soma necessária para aquisição da arma, Emma toma dinheiro emprestado à sua irmã, e finalmente compra a

sociais. Richard Rorty também vê com muito desalento o que também chama de "esquerda cultural" em RORTY, Richard. Para Realizar a América: o pensamento de esquerda no século XX na América. Rio de Janeiro: DP\&A editora, 1999.

20 Entre os principais nomes dessa esquerda literária estariam Max and Crystal Eastman e Mabel Dodge, que mantinha as portas de seu apartamento na Quinta Avenida sempre abertas para todos os que desejassem experimentar o novo no sentido de fundir arte e política. Diggins também inclui outros nomes como Walter Lippmann e Randolph Bourne.

21 V. MORTON, Marian J. Emma Goldman and the American Left. Nowhere at Home. New York: Twayne Publishers, 1992.

22 Ver Emma Goldman and the American Dissent. In: WALKER, Martin. America Rebom: Twentieth-Century Narrative in Twenty-six Lives. New York: Alfred A. Knopf, 2000, p.17. 
arma que, nas mãos de Berkman, deveria detonar o processo revolucionário. Mas seus planos novamente não se realizam a contento: Berkman fere, mas não mata o presidente da empresa e é imobilizado e preso antes de conseguir engolir o veneno que levava consigo caso falhasse. Dos trabalhadores e das lideranças sindicais, majoritariamente constituídas por trabalhadores qualificados, não veio a reação esperada, ao contrário. A forte repressão e o impacto negativo na imprensa fez com que o ato isolado dos dois fosse visto por muitos sindicalistas como um grande erro. Sequer desconfiavam que Goldman iria além: planejava dinamitar o tribunal caso Berkman fosse condenado à morte. Mas, felizmente esta não foi a sentença: pela tentativa de assassinato, Berkman é condenado a quatorze anos de prisão.

Afamada e perseguida por sua ligação com Berkman e por sua oratória brilhante, Goldman foi presa um ano depois, em 1893, acusada de incitamento à desordem, após um discurso na Union Square. Por sua notoriedade, Goldman recebeu assistência jurídica e foi condenada a apenas um ano de prisão.

Após sua libertação, voltou à Europa, encontrando em Londres com lideranças internacionais do anarquismo, especialmente Kropotkin, cujo humanitarismo impressionou Goldman que, a partir dali, o assumiu como principal referência política. Na Europa, Emma estudou enfermagem obstétrica, o que a habilitou a exercer a função de enfermeira-parteira ao voltar aos EUA em 1896. A partir dessa experiência, Goldman associa à sua militância anarquista bandeiras como o controle da natalidade e o amor livre, temas ainda tabus para a época. ${ }^{23}$

Em setembro de 1901, aos 32 anos, Emma Goldman voltaria a ser presa, acusada de incitar o assassinato do presidente Mc Kinley, baleado por Leon Czolgosz, um anarquista desempregado. Em maio, meses antes do crime, o responsável confesso pelo disparo ouvira uma das preleções de Goldman em Cleveland. Apesar de Leon afirmar que agira sozinho, a polícia assumiu a tese de uma conspiração anarquista. Embora Leon fosse norte-americano de nascimento, disseminou-se novamente a perseguição a estrangeiros anarquistas. Reuniões foram proibidas, editoras de jornais anarquistas atacadas e membros do Congresso chegaram inclusive a cogitar a deportação de todos os anarquistas estrangeiros e mesmo o banimento dos norte-americanos. A perseguição aos estrangeiros e ao

23 Goldman não se entusiasmava com a campanha em favor da extensão do direito de voto às mulheres. Em função de sua inserção nos movimentos sociais, não considerava que as mulheres ou qualquer outro segmento da população alcançassem suas demandas através do voto. Em suas palavras: "As a matter of fact, every inch of ground he has gained has been through a constant fight, a ceaseless struggle for self-assertion, and not through suffrage. There is no reason whatsoever to assume any woman, in her climb to emancipation, has been, or will be, helped by the ballot". (Na verdade, cada polegada do chão foi conquistada pela luta, uma luta incessante pela auto-afirmação e não através do sufrágio. Não há qualquer razão para acreditar que qualquer mulher, em sua busca da emancipação, tenha sido ou venha a ser auxiliada pelo voto. Tradução da autora.). Apud: Emma Goldman spreading anarchy in the U.S.A. In: MICHEY, Z. 50 American Revolutions you're not supposed to know: reclaiming American Patriotism. New York: Disinformation Company, 2005, p.45. 
anarquismo recebeu moldura legal com a aprovação do Aliens Act, ${ }^{24}$ de 1903, que criminalizava toda doutrina que advogava a derrubada de um governo organizado pela força.

Goldman acabaria inocentada, mas o caso dividiu a esquerda americana. Os socialistas se afastaram dos anarquistas e, entre os próprios anarquistas, a proposição de Kropotkin por ação coletiva e não violenta como forma de resistir ao Estado passou a ser preferida em relação à violência revolucionaria pregada por Bakunin. ${ }^{25}$ Embora já tivesse revisto sua posição sobre o assunto, em parte em função do seu sofrimento e culpa pela inútil prisão de Berkman, Goldman discordava da posição de muitos da esquerda de abandonar Leon. Defendia não confundir a condenação do assassinato com a defesa do assassino, para ela, vítima da violência do próprio sistema, que teria provocado seu desequilíbrio mental.

Tentando coletar fundos para sua defesa, diria ela:

É a violência organizada no topo que cria a violência individual na base. É a indignação acumulada contra o mal organizado, o crime organizado, a injustiça organizada que leva o individuo a cometer o crime político. Condená-lo simplesmente significa fechar os olhos para os fatores que o constituíram. Eu não posso fazer, eu não tenho direito de fazê-lo, tanto quanto um médico não pode condenar um paciente pela sua doença. Você e eu e todos nós que nos mantemos indiferentes aos crimes da pobreza, da guerra, da degradação humana, somos igualmente responsáveis pelo ato cometido pelo criminoso político.

Goldman encontraria novo estímulo e companheiros para militância ao fundar a Free Speech League (Liga pela Liberdade de Expressão), em 1903, descobrindo nessa bandeira uma forma de aproximar os liberais e radicais nativos dos imigrantes. O processo de americanização das lideranças e das organizações de esquerda avançava. Eugene Debs surgiu como importante líder de um novo partido socialista, o Partido Socialista da América. Embora tivesse como meta a revolução, o partido adotava uma estratégia gradualista e apoiava reformas como a taxação de renda progressiva, proteção ao trabalho infantil e regulação dos monopólios. Goldman aproximou-se

24 Alien é um não cidadão, um estrangeiro. Mas na etmologia da palavra também está presente a idéia da diferença em termos de natureza ou caráter. Alienate se relaciona ao sentimento de indiferença ou hostilidade ou à idéia de confisco. Um illegal alien é um alien cuja presença no território americano é ilegal por ter cruzado a fronteira de forma ilegal ou por ter cometido um crime, o que o torna também um criminal alien. Aos illegal aliens também se aplica o termo undocumented migrant, mas esse uso tem sido significativamente menos utilizado, tanto quanto o termo immigrant que, no imaginário norte-americano, pressupõe um caminho para a condição de residente legal permanente e possível naturalização e aquisição de cidadania. Note-se que o termo alien é utilizado para designar também alienígenas, extraterrestres tenebrosos, como o da série de filmes com esse nome produzidos por Hollywood. Mas não se pode esquecer que a legislação sobre imigração que utiliza este termo remonta ao século XIX, quando evidentemente o imaginário sobre os extraterrestres não estava presente. No contexto atual, é impossível deixar de perceber a associação entre guerra ao terrorismo e aos chamados illegal aliens, envolvendo a emergência de mais uma forma de percepção da diferença cultural como absoluta alteridade, inferioridade intrínseca e perigo. Ver a este respeito NGAI, Mae. Impossible Subjects: illegal aliens and the making of modern America. Princeton \& Oxford: Princeton University Press, 2004.

25 V. FALK, Candace. Love, anarchy and Emma Goldman. Holt Rinehart \& Wiston, 1984. 
igualmente de uma outra organização nativa que lideraria as principais greves a partir de então - a Industrial Workers of the World - cujo criador, Big Bill Haywood, era celebrado como um "real filho do Oeste Americano", um frontiersman do proletariado radical.

Tendo em mente alcançar e atrair apoio do público norte-americano, Goldman passou a publicar um jornal em inglês - Mother Earth - que circulou de 1906 até 1918, quando foi fechado pelo governo federal. Além de reproduzir textos de Proudhon, Kropotkin e outros anarquistas, Mother Earth também discutia o pensamento de Thomas Paine, Emerson, Thoreau e líderes abolicionistas e pacifistas como William Garrison, acrescentando discussões sobre controle da natalidade e resistência ao alistamento militar.

A "americanização" de Goldman também poderia ser verificada na sua tentativa de conciliar a tradição européia anarquista de coletivismo com o individualismo que ela primeiro admirou em Nietzsche e que foi reforçado pelo liberalismo e anarquismo americano. No Congresso Internacional Anarquista de 1907, em Amsterdã, Goldman tentou convencer seus ouvintes de que o anarquismo oferecia "a possibilidade de organização sem disciplina ou punição e sem a pressão da pobreza". Num artigo publicado no New York World, em 1908, ao descrever o anarquismo, Goldman considerou que seu fim era a criação de cooperativas voluntárias, comunidades e sociedades vinculadas de forma livre, cujo objetivo último seria a liberação das latentes disposições individuais, o que não implicaria em qualquer conflito com o coletivo. ${ }^{26}$

Ao voltar para os EUA, Emma se defronta com o crescimento dos preparativos para a entrada na Primeira Guerra Mundial, paralelamente à deportação de imigrantes e à perseguição aos opositores da política externa do presidente Wilson, e volta-se de forma crescente para a campanha contra o alistamento militar.

Num discurso proferido em 1910, intitulado "Patriotismo: uma ameaça à sociedade", Goldman começa por apontar dados sobre o dispêndio crescente e descabido com armamentos, mostrando que os EUA, entre 1881 e 1905, teriam triplicado o montante investido em armas. Acompanhando esta delirante sangria dos cofres públicos, Goldman ataca a tentativa do governo de explorar o sentimento patriótico para mobilizar a população a se oferecer em sacrifício. Reproduz sentenças famosas e lança outras que também virarão lema entre os pacifistas, como veremos posteriormente. Vale citar alguns trechos:

26 Num ensaio publicado em 1911, define anarquismo como "a filosofia de uma nova ordem social baseada na lei humana da liberdade irrestrita, na teoria de que todas as formas de governo se baseiam em violência e que, portanto, são erradas e maléficas, além de desnecessárias...". 
O argumento de que o exército e a marinha em prontidão são a melhor forma de garantir a paz é tão absurda quanto a proposição de que os mais pacíficos cidadãos são aqueles que andam com armamento pesado.

O que é o patriotismo: o amor ao lugar onde se nasceu, o lugar das lembranças, esperanças, sonhos e brincadeiras da infância? Se isso fosse patriotismo, poucos Americanos hoje poderiam se considerar patrióticos, porque o lugar dos jogos infantis se transformou em fábricas, moinhos e minas. (...) Leon Tolstoi, o grande antipatriota de nossos tempos, define patriotismo como o princípio que justifica o treinamento de assassinos.

Patriotismo (...) é a superstição artificialmente criada e mantida através de uma rede de mentiras e falsidades; uma superstição que rouba o auto-respeito e a dignidade e aumenta a arrogância e a vaidade (...) Patriotismo exige fidelidade à bandeira, o que significa obediência e prontidão para matar pai, mãe, irmão, irmã.

Ainda neste discurso, Goldman afirma que a Guerra Hispano-Americana foi, na verdade, fruto daqueles que se preocupavam com o preço do açúcar e não com a liberdade de Cuba. Com certeza usaria o mesmo raciocínio em relação à atual guerra do Iraque.

Incluindo-se entre os americanos, afirma ainda neste discurso de 1910:

Nós Americanos reivindicamos que somos amantes da paz. Que odiamos o derramamento de sangue; que nos opomos à violência. No entanto nos enchemos de alegria quando vislumbramos a possibilidade de lançar bombas de dinamite de máquinas voadoras sobre pessoas indefesas. Estamos prontos a enforcar, eletrocutar e linchar qualquer um que se atreva a avançar sobre um magnata. Entretanto nossos corações se enchem de orgulho quando pensamos que a América está se transformando na maior potência da terra e que eventualmente irá sobrepor seus pés de ferro sobre o pescoço de outras nações.

Emma termina o discurso lamentando o fato de que um soldado tenha sido julgado e condenado pelo simples fato de tê-la cumprimentado, o que demonstrava, a seu ver, que os direitos do cidadão, garantidos pela Declaração da Independência, não eram respeitados nas Forças Armadas. Fica claro neste discurso que Goldman, tendo em mente o público norteamericano, argumentava que a guerra agigantava os poderes do governo, o que traía os princípios originais do americanismo, aqueles que Jefferson tinha em mente quando dizia que o melhor governo era o que governava menos; a América pela qual Thoreau também lutava, afirmando que o melhor governo é o que não governa.

Em 1917, já no curso da guerra e depois de libertado da prisão, Berkman organiza a Liga Contra o Recrutamento. Com a perspectiva de aprovação do Selective Service Act que obrigava os homens entre 20 e 30 anos a se alistar, a campanha cresceu, unindo vários segmentos da esquerda e também dos liberais. A lei foi aprovada e Goldman faz publicar na edição seguinte de 
Mother Earth a manchete "In Memoriam: A Democracia Americana". Neste número descrevia-se o propósito da Liga Contra o Recrutamento, encorajando-se os leitores a afirmar e traduzir sua liberdade individual assumindo a posição de objetores conscientes da guerra. Mas ia-se mais além, afirmando a oposição não só à guerra em curso, mas às conseqüências da crescente militarização.

Enquanto isso, a polícia prendia os que se manifestavam em favor da objeção consciente à guerra e mesmo aqueles que eventualmente não portassem comprovantes de alistamento. ${ }^{27}$ Manifestação de qualquer natureza em frente à Casa Branca era reprimida e os manifestantes presos. Professores que se manifestavam contra a guerra eram demitidos.

Em junho de 1917, no dia seguinte a uma manifestação contra o alistamento, Goldman e Berkman foram presos acusados de conspiração. A Lei contra Espionagem seria aprovada no dia 15 de junho, dias depois.

No dia do julgamento, assumindo sua própria defesa, Goldman proferiu um discurso seguindo seu estilo inflamado e sarcástico, denunciando o sentido político de todo o processo movido contra ela e Berkman, que continha flagrante desrespeito às regras processuais vigentes, mencionando mais uma vez que atentava-se contra os direitos inscritos na Constituição e na Declaração de Independência. Suas palavras não parecem distantes da realidade de hoje. Cito:

Acusar-nos de conspiração por fazer aquilo que sempre estivemos fazendo ao longo da maior parte de nossas vidas, nomeadamente a campanha contra a guerra, o militarismo e o alistamento forçado, contrariando os melhores interesses da humanidade, representa um insulto à inteligência. (...) Nós dizemos que se a América estivesse entrando na guerra para salvar o mundo para a democracia, ela deveria primeiro salvar a democracia na América. Como o mundo pode levar a América a sério se a democracia aqui é diariamente ultrajada, a liberdade de expressão suprimida e as assembléias pacíficas reprimidas por gangsters brutais usando uniforme; quando a liberdade de imprensa é limitada e cortada a independência de opinião. Certamente, pobres como somos em termos de democracia, como podemos nós dá-la ao mundo? Nós demonstramos que a democracia concebida da servidão militar das massas, na escravidão econômica e nutrida em suas lágrimas e sangue, não é absolutamente democracia. É despotismo - o resultado acumulado de uma cadeia de abusos, que de acordo com um documento muito perigoso - a Declaração de Independência - o povo tem o direito de derrubar. (...) A história do desenvolvimento da humanidade equivale ao anúncio por novas idéias de uma novo alvorecer, que é sempre considerado ilegal, fora da lei.

27 ZINN, Howard. A People's History of the United States. Nova York: Harper Perennial, 1995. 
É significativo que a Declaração de Independência seja mais uma vez citada e que Emma recorra também a outros elementos da narrativa da fundação da nação:

Senhores jurados (...) eu assumo que os senhores se orgulham do seu Americanismo. Lembrem que aqueles que lutaram e deram seu sangue por sua liberdade eram no seu tempo considerados fora da lei, perigosos perturbadores da ordem e criadores de caso. Eles não apenas pregaram a violência, mas colocaram em prática suas idéias jogando o chá nas águas da baía de Boston. Eles disseram 'Resistir à tirania é obedecer a Deus'. (...) Eles eram os anarquistas daquele tempo - eles nunca estiveram de acordo com a lei.

Podemos imaginar que os jurados tenham imaginado que Emma estivesse se valendo de uma estratégia para parecer mais "Americana", mas em função do que já foi dito, considero que estivesse afirmando a legitimidade da apropriação e da luta em torno dos ideais americanos. Vejamos as palavras finais de seu discurso:

Eu poderia lembrá-los de dois grandes Americanos, certamente não desconhecidos dos senhores jurados - Ralph Waldo Emerson e Henry David Thoreau. Quando Thoreau foi colocado na prisão por se recusar a pagar impostos, recebeu a visita de Emerson, que Ihe perguntou: 'David o que faz você na cadeia?' E Thoreau respondeu: Ralph, o que você está fazendo aí fora, quando homens honestos estão na cadeia por seus ideais?

Eu conheço muita gente - e eu sou uma delas - que não nasceu aqui, ou não requereu cidadania, e que ainda assim amam a América com paixão mais profunda e maior intensidade que muitos nativos, cujo patriotismo se manifesta atacando e insultando aqueles que não se levantam quando o hino nacional é tocado. Nosso patriotismo é aquele do homem que ama uma mulher com os olhos abertos. Que se encanta com sua beleza, mesmo que perceba suas falhas. Então, também nós que conhecemos a América, que amamos sua beleza, sua riqueza, a grandeza de suas possibilidades, que amamos suas montanhas, seus canyons, suas florestas, Niagara, seus desertos e, acima de tudo, o povo que produz sua riqueza, os artistas que criam belezas, com a mesma intensa emoção odiamos sua superficialidade, hipocrisia, corrupção, loucura e inescrupulosa devoção à riqueza material. ${ }^{28}$

O júri não se comoveu. Na verdade confrontava o júri com uma versão de americanismo muito distinta do American creed hegemônico. Goldman e Berkman foram condenados. O juiz recomendou a deportação dizendo: "Não temos lugar neste país para aqueles que expressam o pensamento de que a lei pode ser desobedecida de acordo com a escolha dos indivíduos". A Suprema Corte também rejeitou o recurso impetrado invocando a déci-

28 Trial and Speeches of Alexander Berkman and Emma Goldman in the United States District Court, in the City of New York, July, 1917 (New York: Mother Earth Publishing Association [1917]), p.56-66. (Tradução minha). 
ma terceira Emenda, contra a servidão; a primeira Emenda, que protege a liberdade de expressão; e a décima quinta, que garante o justo processo. Após dois anos na prisão, em 1919, aos 50 anos, Goldman deixava os EUA com Berkman, não sem antes se comover com a situação que presenciou em sua passagem por Ellis Island, onde centenas de estrangeiros, homens e mulheres, aguardavam deportação, em muitos casos, sem terem sido sequer submetidos a um julgamento. A esta altura, o Alien Enemy Bureau e o Bureau of Investigation (BI), vinculados ao Departamento de Justiça, funcionavam a todo vapor, sob a liderança de um personagem que se tornaria chave na história norte-americana por várias décadas: J. Edgar Hoover. A deportação de Emma representou uma grande vitória de Hoover, que conseguiu invalidar a cidadania de Goldman, adquirida com o breve casamento com Jacob Kersner, em 1887, comprovando que a própria cidadania de Kersner tinha sido cassada antes de sua morte. A partir do caso Emma, consolidou-se um padrão de operação e investigação dos envolvidos com o movimento pacifista e outros movimentos considerados ameaçadores da ordem e da segurança nacionais que envolvia intimidação através de expedientes como invasão de domicílio, apreensão ilegal de documentos, despejo, cerceamento ao direito de expressão etc. ${ }^{29}$

A chegada de Emma e Berkman à Rússia não Ihes abriria novos horizontes. Embora tenham sido agraciados com toda a cortesia reservada a eminentes militantes da esquerda, sendo recebidos inclusive pelo próprio Lênin, Goldman e Berkman logo descobririam que a revolução na qual tinham depositado tantas esperanças também executara e encarcerara anarquistas e outros dissidentes. Da boca do próprio Lênin ouviram que a liberdade de expressão era um conceito burguês. De Maksim Gorki escutaram que as massas selvagens não eram a vanguarda, mas um obstáculo à revolução e que o gênio de Lênin é que a sustentaria. A extrema penúria em que vivia a população também aumentava sua desilusão. Testemunhar a forma como foi esmagado o levante dos marinheiros do Kronstadt em 1921 foi a gota d’água. Depois de deixar a URSS, Goldman descreveria seu retorno à terra natal e as duras experiências por que passara no livro Minha desilusão com a Rússia. Concluía que a ditadura do proletariado, tanto quanto o capitalismo, não era aceitável. Se podia admitir a violência acompanhando o início de um processo revolucionário, não podia aceitar sua institucionalização, muito depois dos inimigos externos e internos terem sido derrotados.

Vigiados tanto pela polícia política soviética quanto por agentes do Departamento de Estado norte-americano, Goldman e Berkman passam por vários países da Europa. Goldman fica dois anos na Alemanha, mas não

29 Ver Emma Goldman and the American Dissent. In: WALKER, Martin. America Reborn: Twentieth-Century Narrative in Twenty-six Lives. New York: Alfred A. Knopf, 2000, p.17. 
conseguindo mais se expressar com facilidade em alemão, decide ir para Inglaterra, onde, em 1926, aceita oferta de casamento de um anarquista viúvo. Adquire assim cidadania inglesa e deixa de usar seu passaporte de apátrida emitido pela Liga das Nações. Em 1928 vai para França onde começa a escrever sua auto-biografia - Living my Life.

Junto com o suicídio de Berkman em 1936, que a deixaria devastada, explode a Guerra Civil Espanhola, que a traria de volta para a cena política, a pedido dos anarquistas. Mas embora não revelasse publicamente, Goldman não conseguia evitar o desconforto com a violência que se desenrolava. A angústia que vivia é nitidamente revelada em suas palavras:

Sou no coração uma rebelde, uma anarquista, uma herética. Mas minhas associações e experiência me ensinaram uma maneira de viver na qual somente parte disso é revelado. Fico então entre a respeitável e a pária, em desgraça por ambos os lados. (...) Eu me sinto tão deslocada, repelida, tomada por fúrias e em lugar algum tenho a sensação de estar em casa. ${ }^{30}$

A Revolução Espanhola, como preferiam chamá-la os anarquistas, é derrotada, os governos fortes emergem em toda a Europa e se torna muito perigoso para uma judia anarquista permanecer lá. Nos EUA, Roosevelt e seu welfare state recebem apoio dos liberais e até mesmo da esquerda. Mesmo assim, Emma anseia por voltar. Numa carta, Goldman explica seus fortes vínculos com os EUA: "América é realmente uma questão de vida ou morte para mim... É meu último recurso para justificar minha vida diante de mim mesma".

De fato, embora tenha vivido e lutado em vários países e várias frentes, foi nos EUA que Emma passou o maior e o mais bem sucedido período de sua militância política, envolvendo-se profundamente com os principais movimentos sociais, sindicais, feministas e pela liberdade de pensamento e expressão. Embora constantemente perseguida pela polícia, Emma viajou intensamente pelo país, falando, no período mais fecundo do Mother Earth a aproximadamente 50.000 pessoas por ano. Foi também nos EUA onde foi mais feliz, do ponto de vista pessoal. Casou várias vezes e viveu inúmeros relacionamentos, muitas deles com homens bem mais jovens, causando certo escândalo pelos comentários desabridos sobre sua vida amorosa e sexual. ${ }^{31}$ Infelizmente, para sua desilusão, Emma não consegue acabar seus dias nos EUA. Só consegue autorização para realizar um tour de noventa dias em 1934, sob severa vigilância. Em 1940, aos 71 anos, morre no Canadá. Suas cinzas vão para o Waldheim Cemetery, repousar ao

30 "I am a rebel, an anarchist, a heretic at heart. But my associations and backgrounds have given me a method of life which only partially discloses it. I am also therefore between the outcast and the respectable, damned by sections of both". (site American Distress)

31 Ver WEXLER, Alice. Emma Goldman: An Intimate Life. NY: Pantheon, 1984 
lado dos mártires da Haymarket Square. E, como eles, a batalha em torno de sua memória revela a importância de suas ações em vida.

Em 2004 foi exibido na TV o documentário Emma Goldman. ${ }^{32}$ Goldman é retratada como uma outsider, cujo maior talento era o sensacionalismo. As primeiras cenas são da deportação da "radical perigosa". Não é preciso muito esforço para reconhecer a xenofobia conservadora do pós 11 de setembro neste filme. A correlação fica ainda mais explícita quando Alexander Berkman é descrito como um homem bomba suicida. O filme destaca o envolvimento de Emma com a tentativa de assassinato político que levou Berkman à prisão, sua prisão pelo suposto incitamento ao assassinato de Mc Kinley, sua oposição à Primeira Guerra Mundial, seus sucessivos casos amorosos, terminando com seu exílio, isolamento e morte. A participação na Guerra Civil Espanhola é omitida, enquanto que os excessos bolcheviques são sublinhados. Goldman é apresentada por entrevistados como tendo uma personalidade intolerável, impiedosa e vingativa, "totalmente inaceitável por quem se considere progressista, pelas pessoas cultivadas, por qualquer um".

Ao mesmo tempo, no último 4 de julho, entre diversas celebrações pelo dia da Independência, numa manifestação em Orlando denominada Food not Bombs (Comida não Bombas), jovens manifestantes exibiam cartazes com frases de Goldman para protestar contra a guerra no Iraque. Inúmeros sites de organizações que criticam a guerra citam Goldman e vendem camisetas com seu rosto e suas palavras estampadas. ${ }^{33} \mathrm{Um}$ deles - Code Pink Women's Preemptive Strike for Peace (Código Rosa - Greve Preventiva das Mulheres pela Paz), realiza manifestações lúdicas e performances com forte impacto visual e reivindicam seu legado ao usar como lema uma célebre frase de Goldman "If I can't dance, I don't want to be part of your revolution". (Se eu não puder dançar, não quero fazer parte de sua revolução"). ${ }^{34}$

O que parece estar se verificando, na verdade, é uma segunda retomada de Emma Goldman, já que nos anos 60 seu rosto já estampava camisetas de feministas e pacifistas. Vale a pena reproduzir o relato de Carol Sternhell, uma ex-militante:

Com certeza conheci Goldman como um rosto estampado numa camiseta muito antes de saber qualquer coisa sobe sua militância política. Para os jovens dos anos 60 que pensavam que o rock ajudaria a acabar com a guerra - "Façam greve porque não há poesia em suas aulas" eram as palavras do meu pôster

32 Nebrasca ETV Network, direção de Mel Bucklin.

33 Ver por exemplo storesense2. megawebservers.com/stores/h/HS260 (consulta em 16/4/2004). Neste site, além de camisetas com o rosto de Emma Goldman estampado, também encontra-se camisetas com dizeres de Berkman, dos Mártires de Haymarket Square, entre outros anarquistas e ícones do dissenso.

34 codepinkportland.org/ consulta em 16/4/2007. No filme V de Vendetta (2005), dirigido por James McTeigue, o terrorista libertário, que se auto-denomina somente como "V", reproduz esta frase em seu diálogo com a personagem Evey Hammond. 
favorito daquele tempo - a anarquista dançarina era uma aliada espiritual. Nós protestamos em seu nome sem saber muito sobre sua própria luta contra o alistamento militar e contra 'todas as guerras movidas pelos governos capitalistas'. Quando as feministas descobriram que o pessoal era político, Goldman se transformou num modelo, de conteúdo extremamente contemporâneo. ${ }^{35}$

Na ocasião deste depoimento, Sternhell, jornalista e também professora da New York University, queixava-se de que, com exceção de um, que imaginava que tivesse sido Primeira-Ministra de Israel, seus alunos nunca haviam ouvido falar de Emma Goldman.

Felizmente, no entanto, Red Emma, que viveu sua vida com toda intensidade, expondo-se publicamente em vários sentidos, canalizando uma energia verdadeiramente erótica para sua militância política - a "mulher mais perigosa da América" ou uma "Joana D'Arc moderna" ${ }^{6}$ para seus contemporâneos -, parece estar recuperando o lugar que lhe cabe na história, na memória e nas ações da esquerda norte-americana.

35 STERNHELL, Carol. Human, All Too Human. The Nation, 24/11/1984. (Tradução minha).

36 A alcunha lhe foi atribuída por Nellie Bly, jornalista do New York World que a entrevistou em um dos seus períodos na prisão. 